\title{
Clinico-epidemiological Profile of Women with Non- Venereal Vulval Diseases: A Hospital-Based Observational Study
}

\author{
Joshi $\mathbf{S}^{1}$, Shrestha $\mathbf{S}^{1}$, Joshi $\mathbf{A}^{2}$ \\ ${ }^{1}$ Department of Dermatology and Venereology, ${ }^{2}$ Department of Gynecology and Obstetrics, Nepal Medical College \\ Teaching Hospital, Attarkhel, Gokarneshwor, Kathmandu, Nepal
}

\begin{abstract}
Introduction: Vulval disorders can be of venereal and non-venereal etiology. Establishing non-venereal causation of vulval disorder helps in alleviating fears in patients with the condition. These patients are better dealt in a multidisciplinary clinic as patients with these disorders frequently visit dermatologists and gynecologists for the treatment.

Objectives: To study the clinico-demographic profile of women with non-venereal vulval disorders and to determine their relative frequency.

Materials and methods: This is an observational, descriptive study done at the Departments of Dermatology and Venereology and Gynecology and Obstetrics, Nepal Medical College Teaching Hospital. All consenting female patients with problems pertaining to female external genitalia were recruited for the study after excluding venereal diseases. Details of the patients were obtained and entered in a predesigned proforma.

Results: Seventy-five females were recruited during a period of 20 months with a mean age of $34.79 \pm 17.90$ years. Majority were married, uneducated and homemakers. Duration of disease ranged from three days to 35 years. Itching was the commonest presenting complaint (82.67\%) followed by redness (32.00\%), burning sensation (26.67\%), white lesions $(24.00 \%)$ and pain (24.00\%). Commonest diagnosis was lichen sclerosus (17.33\%), followed by candidiasis (14.67\%). Patients presenting with vulval symptoms without lesions were diagnosed with non-specific vulval pruritus (9.33\%) and vulvodynia (2.67\%).
\end{abstract}

Conclusion: Itching is the most common presenting complaint and contrary to the popular belief, inflammatory disorders especially lichen sclerosus, rather than infections were common diagnoses in females with non-venereal vulval disorders.

Key words: Lichen Sclerosus et Atrophicus; Pruritus Vulvae; Vulvodynia

\section{Introduction}

D isorders of female external genitalia are far and wide and encompasses spectrum of diseases ranging from inflammatory disorders, autoimmune diseases, infections, benign and malignant neoplasms. ${ }^{1}$ Diseases involving vulva may be broadly classified into those of venereal and non-venereal etiology. Non-venereal diseases of vulva may be mistaken for venereal diseases, thus escalating mental distress and guilt in patients and may be a cause for marital disharmony. Furthermore, associated symptoms

Address of Correspondence:

Dr. Smita Joshi, MD

Lecturer

Department of Dermatology and Venereology

Nepal Medical College Teaching Hospital, Attarkhel

Gokarneshwor, Kathmandu, Nepal

E-mail: smitaz@nmcth.edu range from common problems like itching to difficulty in maintaining a healthy sexual relationship and may result in a range of physical, psychological and psychosomatic manifestations. ${ }^{2}$

Submitted: $28^{\text {th }}$ October 2018

Accepted: $30^{\text {th }}$ January 2018

Published: $31^{\text {st }}$ March 2019

How to cite this article

Joshi S, Shrestha S, Joshi A. Clinico-epidemiological profile of women with non-venereal vulval diseases: a hospitalbased observational study. Nepal Journal of Dermatology, Venereology and Leprology. 2019;17(1):32-8. doi: http://dx.doi. org/10.3126//njdvl.v17i1.23250

\section{(c) (i)}

Licensed under CC BY 4.0 International License which permits use, distribution and reproduction in any medium, provided the original work is properly cited. 
The prevalence of females with vulval diseases from a tertiary health center in eastern Nepal was reported to be $1.9 \% .^{3}$ This would be just the tip of the iceberg as female are generally poorly represented in the hospital statistics in a developing country like Nepal, where women generally tend to downplay their illness over other important matters of family and society. The private nature of illness and the embarrassment one feels while letting the other person examine the part in question makes the matter worse.

Diseases of female external genitalia, being a gray area, as to whether gynecologists or dermatologists are at better position to treat the condition, pose further problem in management of patients. Patients seek consultation from multitude of specialists, resulting in frustration in the patient and the treating physician. This study aims to determine the demographic profile, relative frequency and characteristics of non-venereal vulval diseases in Dermatology and Gynecology Clinic of a tertiary hospital.

\section{Materials and Methods}

The study is a cross-sectional, descriptive study conducted at the Out-patient Department of Dermatology and Venereology, and Gynecology and Obstetrics, Nepal Medical College Teaching Hospital during a period of 20 months (October 2016 - May 2018). Ethical approval was obtained from Institutional Review Committee (IRC), Nepal Medical College.

All female patients of any age with symptoms or lesions pertaining to external genitalia were screened for presence of non-venereal vulval disorders. Informed consent was obtained from the patients and guardians of minors with newly diagnosed, non-venereal vulval diseases for inclusion in the study. Cases with venereal etiology were excluded from the study. Details of the patient including age, place of residence, educational status, marital status, occupation, symptoms, duration of disease, menstrual history, obstetric history, associated cutaneous and medical illness were obtained. A comprehensive clinical examination and a thorough examination of the external genitalia were done in adequate light. Sites of involvement were noted. Investigations like Gram's stain, Potassium hydroxide mount, bacterial culture and sensitivity, routine and microscopic examination of urine and stool, routine blood examination, serological tests for venereal diseases (Human Immunodeficiency Virus antibody, Venereal Disease Research Laboratory test for syphilis, Herpes antibody titre), biopsy and histopathological examination etc. were advised to be done in respective labs as and when indicated to support the diagnosis.
Final diagnosis was based on clinical judgement and/ or investigations made jointly by a dermatologist and a gynecologist. Patient particulars, history, examination findings, investigations done, and final diagnosis were entered in a predesigned proforma.

Data obtained were entered in Microsoft Excel 2010 and descriptive statistics were obtained. Quantitative data were tabulated and interpreted in terms of percentage, mean and standard deviation. Qualitative data were represented in numbers and percentage.

\section{Results}

A total of 75 females with non-venereal vulval disorders were included in the study during the study period of 20 months. Mean age of study group was $34.79 \pm 17.90$ years (Range: four months to 75 years) [Table 1]. Majority of patients belonged to $29-38$ years age group [Figure 1]. Thirteen patients (17.80\%) were in the pediatric age group ( $\leq 18$ years). Majority of patients were married (74.67\%) and presently residing in Kathmandu valley (89.33\%). Majority of females had not received any formal education (44.00\%) and were financially dependent (78.67\%) [Table 1].

Duration of illness ranged from three days to 35 years with maximum patients with disease duration of $\leq 1$ month (36.00\%) [Table 1]. Itching was the commonest presenting complaint being observed in 62 individuals (82.67\%) [Figure 2]. Concomitant medical illness was present in 16 females (21.33\%). Other dermatological illness was present in nine individuals (12.00\%) [Table 2]. Positive family history of similar illness was present in one patient each of psoriasis and dermatophytosis.

Labia majora was the commonest site of involvement (58.67\%) [Table 1]. Fifty-eight patients had bilateral involvement (77.33\%). Extra-genital involvement was observed in two patients of candidiasis (inner thigh, groin), two patients of tinea cruris involving vulva (infra-mammary area, groin), and one patient each of Behcet's disease (oral aphthae), lichen simplex chronicus (similar lesion in right shin), herpes zoster (ipsilateral buttock and inner thigh) and vulval eczema (inner thigh). The commonest diagnosis observed was lichen sclerosus (17.33\%). Other common diagnoses in decreasing order of frequency were candidiasis (14.67\%), vulval eczema (10.67\%) and non-specific vulval pruritus (9.33\%). Among those presenting without any skin lesion, seven had the diagnosis of non-specific vulval pruritus (9.33\%) and two were diagnosed with vulvodynia (2.67\%) [Figure 3]. 


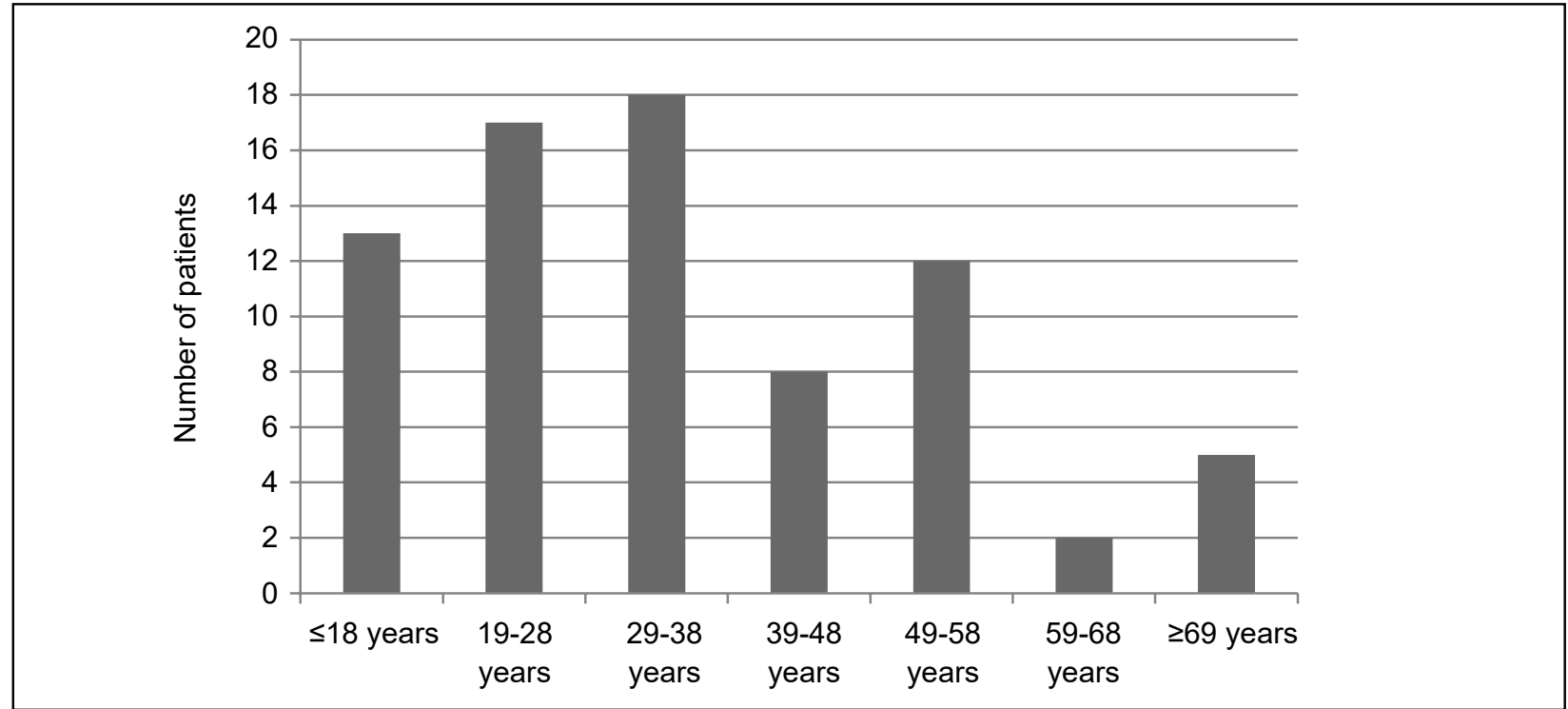

Figure 1: Age distribution in patients with non-venereal vulval disorders.

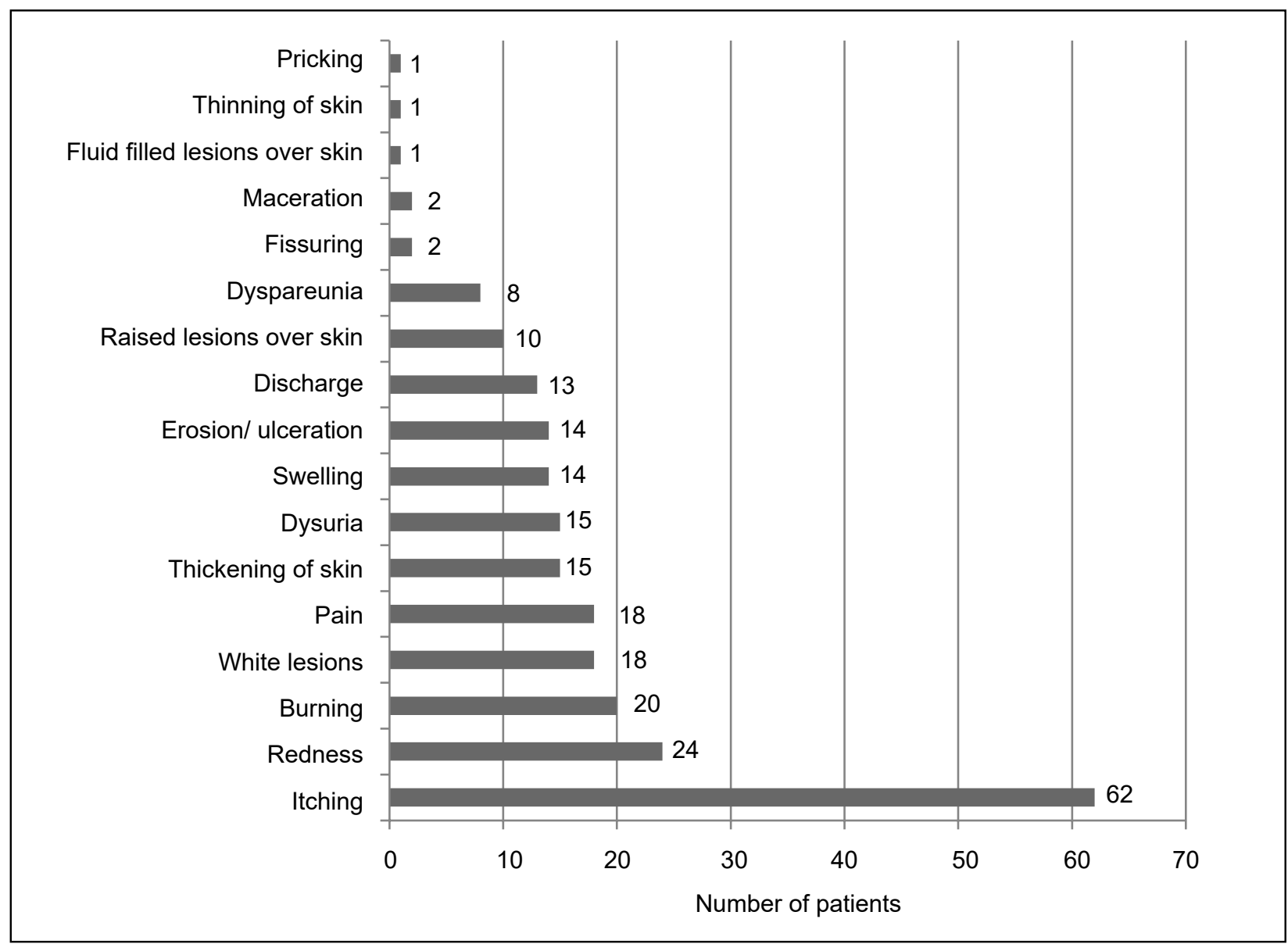

Figure 2: Presentation in patients with non-venereal vulval disorders. 
Table 1: Socio-demographic profile and clinical parameters of study population.

\begin{tabular}{|c|c|}
\hline Mean age & $34.79 \pm 17.90$ years \\
\hline \multicolumn{2}{|l|}{ Marital status } \\
\hline Married & $56(74.67 \%)$ \\
\hline Unmarried & $19(25.33 \%)$ \\
\hline \multicolumn{2}{|l|}{ Residence } \\
\hline Kathmandu valley & $67(89.33 \%)$ \\
\hline Outside Kathmandu valley & $8(10.67 \%)$ \\
\hline \multicolumn{2}{|l|}{ Education } \\
\hline None & $33(44.00 \%)$ \\
\hline Primary & $11(14.67 \%)$ \\
\hline Secondary & $16(21.33 \%)$ \\
\hline Higher Secondary & $9(12.00 \%)$ \\
\hline Undergraduate & $5(6.67 \%)$ \\
\hline Postgraduate & $1(1.33 \%)$ \\
\hline \multicolumn{2}{|l|}{ Occupation } \\
\hline Homemaker & $41(54.67 \%)$ \\
\hline Student & 15 (20.00\%) \\
\hline Unemployed & $3(4.00 \%)$ \\
\hline Employed & $16(21.33 \%)$ \\
\hline \multicolumn{2}{|l|}{ Duration of illness } \\
\hline$\leq 1$ month & 27 (36.00\%) \\
\hline 1 month to $\leq 1$ year & $22(29.33 \%)$ \\
\hline$>1$ year & $26(34.67 \%)$ \\
\hline \multicolumn{2}{|l|}{ Menstrual history } \\
\hline Premenstrual & $9(12.00 \%)$ \\
\hline Menstrual - Regular & 39 (52.00\%) \\
\hline Menstrual - Irregular & $9(12.00 \%)$ \\
\hline Post-menopausal & $18(24.00 \%)$ \\
\hline \multicolumn{2}{|l|}{ Obstetric history } \\
\hline Nulliparous & 27 (36.00\%) \\
\hline Parous & $48(64.00 \%)$ \\
\hline Pregnant & $4(5.33 \%)$ \\
\hline \multicolumn{2}{|l|}{ Sites of involvement } \\
\hline Labia majora & $44(58.67 \%)$ \\
\hline Labia minora & $38(50.67 \%)$ \\
\hline Perineum & $12(16.00 \%)$ \\
\hline Anterior commissure & $11(14.67 \%)$ \\
\hline Mons pubis & $8(10.67 \%)$ \\
\hline Vestibule & 5 (6.67\%) \\
\hline Clitoris & 5 (6.67\%) \\
\hline Fourchette & 5 (6.67\%) \\
\hline
\end{tabular}

\section{Discussion}

Diseases of the vulva are of paramount importance, however are often neglected and can be considered an orphan disease. ${ }^{4,5}$ Although vulva is the most approachable part of female pelvic organ, health practitioners seldom take time to stop and look for its changes. Vulva thus is referred in the literature as "the forgotten pelvic organ". ${ }^{6}$ Vulval maladies often are at
Table 2: Concomitant medical and dermatological illness in study population.

\begin{tabular}{|c|c|}
\hline & $\begin{array}{c}\text { Number of patients } \\
\text { (Percentage) }\end{array}$ \\
\hline \multicolumn{2}{|l|}{ Medical illness } \\
\hline Hypertension & $4(5.33 \%)$ \\
\hline Diabetes mellitus & $3(4.00 \%)$ \\
\hline Hypothyroidism & $2(2.67 \%)$ \\
\hline Acid peptic disease & $2(2.67 \%)$ \\
\hline Osteoarthritis & $1(1.33 \%)$ \\
\hline Depression & $1(1.33 \%)$ \\
\hline Migraine & $1(1.33 \%)$ \\
\hline Asthma & $1(1.33 \%)$ \\
\hline Tuberculosis & $1(1.33 \%)$ \\
\hline $\begin{array}{l}\text { Chronic obstructive } \\
\text { pulmonary disease }\end{array}$ & $1(1.33 \%)$ \\
\hline Enteric fever & $1(1.33 \%)$ \\
\hline \multicolumn{2}{|l|}{ Dermatological illness } \\
\hline Photodermatitis & $2(2.67 \%)$ \\
\hline Hand/ foot eczema & $2(2.67 \%)$ \\
\hline Atopic dermatitis & $1(1.33 \%)$ \\
\hline Chronic urticaria & $1(1.33 \%)$ \\
\hline Palmoplantar psoriasis & $1(1.33 \%)$ \\
\hline Acne vulgaris & $1(1.33 \%)$ \\
\hline Herpes genitalis & $1(1.33 \%)$ \\
\hline
\end{tabular}

disadvantage due to the fact that there is no clear cut distinction as to whether its place lies in dermatology or gynecology. The establishment of inter-disciplinary vulval disease clinic with a team of dermatologists, gynecologists and pathologists working together has found its way especially in developed nations which has greatly increased the clinician's understanding of vulval diseases and "the forgotten pelvic organ", the attention it deserves. ${ }^{7-10}$ Such a concept of vulval disease clinic is still a far-fetched idea in a resource poor country like Nepal.

International Society for the Study of Vulvovaginal Disease (ISSVD) classified the vulval diseases as either vulval dermatoses (for conditions associated with visible skin changes) or vulval dysesthesia (for conditions that cause vulval pain and without visible skin changes). ${ }^{11}$ Vulval dysesthesia encompasses vulvodynia, vestibulodynia, clitorodynia etc. and vulval dermatoses includes inflammatory cutaneous diseases (lichen sclerosus, lichen planus, psoriasis), autoimmune (vitiligo), multisystem illness (Behcet's syndrome, Crohn's disease), exogenous (contact eczema, drug eruptions, infections), benign and malignant neoplasms. ${ }^{1,2}$ 


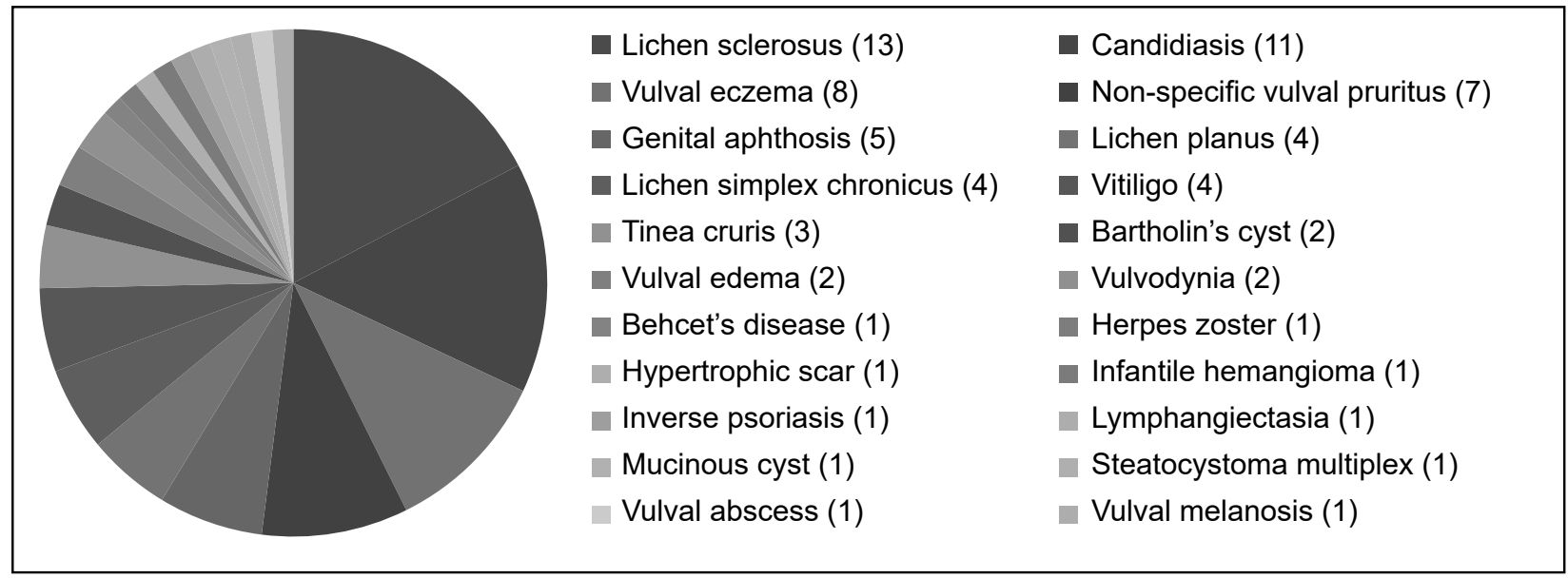

Figure 3: Final diagnosis among patients with non-venereal vulval disorders.

Mean age of 34 years in our study is in concordance with previous studies from India and Turkey evaluating vulval dermatoses, ${ }^{7,12}$ but is slightly higher than the study done in eastern Nepal. ${ }^{3}$ It should be noted that we excluded patients with venereal diseases in the present study as compared to inclusion of venereal and non-venereal vulval diseases in the study by Pathak et al and Gokdemir et al. ${ }^{3,7}$ Nearly $3 / 4^{\text {th }}$ of patients were married which is similar to the results in study by Pathak et al and Singh et al. ${ }^{3,12}$ This is in contrast to the study by Sartori et al wherein majority (58.7\%) were single women. ${ }^{13}$ It should be noted that only $1 / 5^{\text {th }}$ of patients had received higher secondary education or above and $1 / 5^{\text {th }}$ had reported that they were engaged in some form of occupation. This gives a rough portrayal of patient's knowledge, economic dependence, their practices and health seeking behavior, which could be potential barriers in the optimal management of females with vulval diseases. Furthermore, $90 \%$ of the patients in present study were currently residing in Kathmandu valley. The poorer socio-economic and educational status of females in far-flung rural areas of Nepal renders management of readily identifiable and easily treatable vulval conditions more inaccessible to them.

Itching was the predominant symptom in present study $(82.67 \%)$ which is in agreement to the study from eastern Nepal (82.8\%) and two other studies from India $(60 \%$ and $61.7 \%) .3,12,14$. Other common symptoms were redness $(32.00 \%)$, burning sensation (26.67\%), white lesions $(24.00 \%)$ and pain $(24.00 \%)$. Co-morbities were reported in $21.33 \%$ in the present study as compared to $41.30 \%$ in the study by Sartori et al. ${ }^{13}$ Majority of patients were menstrual which is in agreement to the study from eastern Nepal but in contrast to the study from India wherein majority of patients were post-menopausal. ${ }^{3,12}$ Irregular menses were observed in $12.00 \%$ of study population which is similar to the study done by Pathak et al (11.40\%). It should be noted that Pathak et al reported significant association of vulval diseases with irregular menses in their study and raised the possibility of effect of hormonal imbalance leading to epithelial fragility and predisposition to irritation. $^{3}$

Labia majora was the commonest site of involvement in present study which is in concordance with previous studies. ${ }^{12,14}$ We encountered 22 different vulval disorders in our cohort of patients. Among them lichen sclerosus was the commonest condition, being diagnosed in $17.33 \%$ of individuals. Fischer and Rogers evaluated 130 prepubertal girls with vulval complaints and reported commonest diagnosis to be atopic or irritant dermatitis (33\%). Other common disorders included lichen sclerosus (18\%), psoriasis (17\%), hemangioma and nevi (12\%) and streptococcal vulvovaginitis (10\%). ${ }^{15}$ In the present study, out of 13 girls of $\leq 18$ years, lichen sclerosus $(23.07 \%)$ and genital aphthosis (23.07\%) were the commonest diagnoses.

In the study by Gokdemir et al, 33.54\% had specific dermatological conditions, commonest being vitiligo, psoriasis, contact dermatitis and lichen simplex chronicus, $32.25 \%$ had vulval infections and $26.45 \%$ vulval pruritus. ${ }^{7}$ In another study by Hansen et al, similar finding was noted with $47.5 \%$ of women with vulvovaginal complaint having diagnosed with specific dermatological condition. ${ }^{16}$ This emphasized the role of dermatologist in the management of vulval disorders which many consider to be gynecologist's forte. Gokdemir et al further underscored the role of multidisciplinary approach in the management of vulval disorders as patients with same symptoms may be diagnosed differently by dermatologists and gynecologists due to the different training obtained by them. $^{7}$ 
The most common non-venereal dermatosis of female external genitalia was reported to be lichen sclerosus $(21.7 \%)$ by Singh et al from South India in $2008 .{ }^{12}$ This finding is similar to the result in present study. Other common dermatoses in the study by Singh et al. were vitiligo (15.8\%), lichen simplex chronicus (13.3\%), vulval candidiasis $(9.2 \%)$, benign tumors and cysts $(6.6 \%)$ and lymphedema (5.8\%). ${ }^{12}$ Of note, commonest diagnosis in interdisciplinary vulval clinics was also reported to be lichen sclerosus in two different studies. ${ }^{8,9}$ This is in contrast to another Indian study done in 2016 which reported tinea cruris to be the commonest diagnosis in sexually active women. ${ }^{14}$ Similarly, the study from eastern Nepal observed vulval dermatoses in $62.85 \%$ among which vulvovaginal candidiasis was the commonest condition (11.4\%). ${ }^{3}$ In the most recent study from Brazil, the commonest diagnosis was condyloma acuminata (37.3\%) followed by lichen sclerosus (16.0\%). ${ }^{13} \mathrm{Among}$ other factors, these variations in the commonest vulval diseases could be due to different inclusion and exclusion criteria in the present and the aforementioned studies.

Non-specific pruritus vulvae though commonly encountered in clinical practice has been poorly reported in literature. We observed non-specific vulval pruritus in $9.33 \%$ of individuals, ranking fourth amongst the common diagnoses. Pathak et al reported $36.2 \%$ of patients to have pruritus vulvae, majority occurring in children and young women. ${ }^{3}$ Paek et al similarly noted non-specific vulval pruritus in $75 \%$ of pre-pubertal children evaluated for pruritus vulvae which was alleviated or cured by better hygiene and avoidance of irritants. ${ }^{17}$ In contrast, vulvodynia is extensively researched and frequently diagnosed condition with prevalence of $10-15 \%$ in hospital based studies. ${ }^{9,18}$ However, study from eastern Nepal reported vulvodynia in only $0.9 \%$ of patients with vulval diseases and only $2.67 \%$ of patients in the present study were diagnosed with vulvodynia. Simpler standard of living and less psychological stress with mild symptoms were enumerated as possible factors in less number of cases compared to western literature. ${ }^{3}$ Whether that is the case, or patients with vulvodynia are not seeking care and suffering in silence, or dermatologists in our setup are under-diagnosing the condition needs to be explored in future studies.

The study of vulval diseases has gained momentum in recent times especially in western world. ${ }^{19}$ The necessity and benefit of interdisciplinary vulval clinic has been emphasized in various studies and is the obvious way forward in optimal management of these patients. ${ }^{7-10}$ The present study established the burden of non-venereal vulval diseases in Nepalese women in Dermatology and Gynecology clinics of tertiary health center and forms a basis for planning and allocation of resources in this neglected area. Multicenter and community based studies including larger sample size, studies regarding less reported conditions like nonspecific vulval pruritus and vulvodynia and studies concerning impact of vulval diseases in quality of life could be potential areas to explore in future.

This study was a hospital based study, hence is not completely representative of the situation in the community. We did not study the risk factors of vulval diseases and the study does not establish association between cause and outcome. Limited sample size might have lead to exclusion of rare diseases in our study population.

\section{Conclusion}

This study outlined the clinico-epidemiologic profile of women presenting with non-venereal vulval diseases. Patients mostly presented with itching and in contrary to common belief that infections, particularly candidiasis is the commonest cause of consultation, inflammatory condition, specifically lichen sclerosus was the leading diagnosis in a tertiary referral center.

\section{References}

1. Lynch PJ, Moyal-Barrocco M, Bogliatto F, Micheletti L, Scurry J. 2006 ISSVD classification of vulvar dermatoses: pathologic subsets and their clinical correlates. J Reprod Med. 2007;52:3-9.

2. Adams SJ. Vulval dermatoses. In: Kumar B, Gupta $S$, editors. Sexually transmitted infections. $1^{\text {st }}$ ed. New Delhi: Elsevier; 2005. p. 565-76.

3. Pathak D, Agrawal S, Dhali TK. Prevalences of and risk factors for vulvar diseases in

Nepal: a hospital-based study. Int J Dermatol. 2011;50:161-7. https://doi.org/10.1111/j.13654632.2010.04631.x

4. Fischer G, Spurrett B, Fischer A. The chronically symptomatic vulva: etiology and management. $\mathrm{Br}$ J Obstet Gynaecol. 1995;102:773-9. https://doi. org/10.1111/j.1471-0528.1995.tb10841.x

5. Margesson LJ. Vulval diseases pearls. Dermatol Clin. 2006;24:145-55. https://doi.org/10.1016/j. det.2006.01.007 
6. Noller KL. Vulva: the forgotten pelvic organ. Obstet Gynecol. 2004;104:913-4. https://doi. org/10.1097/01.AOG.0000146916.08064.fe

7. Gokdemir G, Baksu B, Baksu A, Davas I, Koslu A. Features of patients with vulvar dermatoses in dermatologic and gynecologic practice in Turkey: is there a need for an interdisciplinary approach? J Obstet Gynaecol Res. 2005;31:427-31. https:// doi.org/10.1111/j.1447-0756.2005.00314.x

8. Sullivan AK, Straghair GJ, Marwood RP, Staughton RC, Barton SE. A multidisciplinary vulva clinic: the role of genitor-urinary medicine. J Eur Acad Dermatol Venereol. 1999;13:36-40. https://doi. org/10.1111/j.1468-3083.1999.tb00841.x

9. Cheung ST, Gach JE, Lewis FM. A retrospective study of the referral patterns to a vulval clinic: highlighting educational needs in this subspeciality. J Obstet Gynaecol. 2006;26:435-7. https://doi.org/10.1080/01443610600747140

10. Tan AL, Jones R, Mcpherson G, Rowan D. Audit of a multidisciplinary vulvar clinic in a Gynecologic Hospital. J Reprod Med.2000;45:655-8.

11. Ridley CM. Classification of cutaneous vulvar disorder - ISSVD. In: Black MM, McKay M, Braude PR, Vaughan-Jones SA, Margesson LJ, editors. Obstetric and Gynecologic Dermatology. 2nd ed. New York: Mosby; 2002. p. 105-8.

12. Singh N, Thappa DM, Jaisankar TJ, Habeebullah S. Pattern of nonvenereal dermatoses of female external genitalia in South India. Dermatol Online J [Internet]. 2008
Jan [cited 2018 Oct 5];14:1. Available from: https://escholarship.org/uc/item/5hs3f52v

13. Sartori GC, Wicher RT, Ferreira FR, Batista VH. Most frequent dermatoses at a vulvar pathology outpatient clinic. An Bras Dermatol. 2018;93:2946. https://doi.org/10.1590/abd18064841.20186784

14. Singh G, Rathore BS, Bhardwaj A, Sharma S. Non venereal benign dermatoses of vulva in sexually active women: a clinical study. Int J Res Dermatol. 2016;2:25-9. https://doi.org/10.18203/issn.24554529.IntJResDermatol20162419

15. Fischer $G$, Rogers $M$. Vulvar disease in children: a clinical audit of 130 cases. Pediatr Dermatol. 2000;17:1-6. https://doi.org/10.1046/ j.1525-1470.2000.01701.x

16. Hansen A, Carr K, Jensen JT. Characteristics and initial diagnosis in women presenting to a referral center for vulvovaginal disorders in 1996-2000. J Reprod Med. 2002;47:854-60.

17. Paek SC, Merritt DF, Mallory SB. Pruritus vulvae in prepubertal children. J Am Acad Dermatol. 2001;44:795-802. https://doi.org/10.1067/ mjd.2001.112578

18. Goetsch MF. Vulvar vestibulitis: prevalence and historic features in a general gynecologic practice population. Am J Obstet Gynecol. 1991;164:160914. https://doi.org/10.1016/00029378(91)91444-2

19. Lewis FM. Vulval disease from the 1800 s to the new millennium. J Cutan Med Surg. 2002;6:340-4. https://doi.org/10.1177/120347540200600406 